\title{
(C) OPEN ACCESS \\ What are the current challenges of managing cancer pain and could digital technologies help?
}

\section{Rosalind Adam, ${ }^{1}$ Marijn de Bruin, ${ }^{2}$ Christopher David Burton, ${ }^{3}$ Christine M Bond, ${ }^{1}$ Maria Giatsi Clausen, ${ }^{4}$ Peter Murchie ${ }^{1}$}

\section{- Additional material is published online only. To view please visit the journal online (http://dx.doi.org/10.1136/ bmjspcare-2016-001232) \\ ${ }^{1}$ Academic Primary Care, Institute of Applied Health Sciences, University of Aberdeen, Aberdeen, UK \\ ${ }^{2}$ Aberdeen Health Psychology Group, Institute of Applied Health Sciences, University of Aberdeen, Aberdeen, UK ${ }^{3}$ Academic Unit of Primary Medical Care, University of Sheffield, Sheffiled, UK ${ }^{4}$ School of Health Sciences, Queen Margaret University, Edinburgh, UK}

\section{Correspondence to} Dr Rosalind Adam, Centre of Academic Primary Care, University of Aberdeen, Room 1:131, Polwarth Building, Foresterhill AB25 2ZD, Aberdeen, UK; rosalindadam@abdn.ac.uk

Received 5 September 2016 Revised 30 January 2017 Accepted 12 April 2017 Published Online First 29 May 2017

\section{Check for updates}

To cite: Adam $R$, de Bruin $M$, Burton CD, et al. BMJ Supportive \& Palliative Care 2018:8:204-212.

\section{ABSTRACT}

Objectives Pain remains a problem for people with cancer despite effective treatments being available. We aimed to explore current pain management strategies used by patients, caregivers and professionals and to investigate opportunities for digital technologies to enhance cancer pain management.

Methods A qualitative study comprising semistructured interviews and focus groups. Patients with cancer pain, their caregivers and health professionals from Northeast Scotland were recruited from a purposive sample of general practices. Professionals were recruited from regional networks.

Results Fifty one participants took part in 33 interviews (eight patients alone, six patient/ caregiver dyads and 19 professionals) and two focus groups (12 professionals). Living with cancer was hard work for patients and caregivers and comparable to a 'full-time job'. Patients had personal goals which involved controlling pain intensity and balancing this with analgesic use, side effects, overall symptom burden and social/physical activities. Digital technologies were embraced by most patients, and made living life with advanced cancer easier and richer (eg, video calls with family). Technology was underutilised for pain and symptom management. There were suggestions that technology could support self-monitoring and communicating problems to professionals, but patients and professionals were concerned about technological monitoring adding to the work of managing illness.

Conclusions Cancer pain management takes place in the context of multiple, sometimes competing personal goals. It is possible that technology could be used to help patients share individual symptom experiences and goals, thus enhancing tailored care. The challenge is for digital solutions to add value without adding undue burden.

\section{INTRODUCTION}

Pain is a distressing complication of cancer, which remains prevalent despite the existence of effective treatments. ${ }^{1}$ 'Barriers' to effective cancer pain management have been described. ${ }^{2}$ Patient beliefs and attitudes, for example, fatalistic beliefs about cancer and negative perceptions of opioids, can adversely affect pain management. ${ }^{3}$ Professional barriers include knowledge deficits about pain management, inadequate pain assessment and suboptimal prescribing. ${ }^{4}$ Healthcare systems can also contribute to suboptimal cancer pain management through discontinuous care and delayed access to appropriate analgesia. ${ }^{5}$ Despite knowledge about potential barriers to optimal cancer pain management, there is currently no coherent explanatory framework to describe how patients and professionals approach cancer pain management, and what influences the actions that they take to control pain.

There are good reasons to believe that digital technologies could help with cancer pain management, for example, through improving informational continuity, and supporting the use of patient-reported outcome measures (PROMs). Electronic health records and computerised anticipatory care plans are already being used by primary care out-of-hour $(\mathrm{OOH})$ services in the UK and can improve patient satisfaction with cancer pain management in the OOH period. ${ }^{6}$ Research is now focusing on digital interventions which target individual patients. ${ }^{7}$ Digital interventions have been developed which allow patients to monitor pain and other symptoms at home. ${ }^{89}$ Some systems generate alerts to health professionals when patient reports of pain or other symptoms reach predetermined thresholds. ${ }^{10} 11$ Others allow patients to view and share pain summaries with their physician. ${ }^{12}$ 
A recent systematic review ${ }^{13}$ found 24 reports of digital systems that had been investigated in cancer pain palliation. The design processes used for these interventions lacked rigour and neglected the perspective of potential end users. None of the interventions had been implemented in clinical practice. Proper attention to the practical issues of implementing interventions, as determined by end users, is important consideration if digital interventions are to be adopted into practice. ${ }^{14}$

The first aim of this study was to explore current pain management strategies used by patients, caregivers and professionals and the factors influencing pain management. The second aim was to understand how digital technologies are currently being used and to explore potential opportunities and preferences for using digital technologies to enhance cancer pain management.

\section{METHODS}

\section{Setting and design}

The study took place in Northeast Scotland. Qualitative semistructured interviews were conducted with patients with cancer pain living in a community setting, their caregivers and healthcare professionals involved in cancer pain management. Interviews were conducted face to face and by telephone. Two multidisciplinary professional focus groups were conducted. Focus groups took place after interviews were already underway, using the same topic schedule, but encouraging in-depth discussion and debate. Focus groups allowed the opportunity for expansion and elaboration on themes emerging from the interviews.

\section{Participants}

Patient participants were adults 18 years or over with established cancer and experiencing associated pain within the preceding 3 months. Patients were recruited from general practices, which were purposively sampled to include urban and rural practices with varying sociodemographic catchment areas. Potential participants were identified by a research assistant from the Scottish Primary Care Research Network who searchedgeneral practice electronic records using diagnostic codes for any cancer (except non-melanoma skin cancer) and for prescription of any analgesic within the past three months (a proxy for recent pain). Records were also checked manually for evidence that the patient had experienced cancer-related pain.

The resulting lists of potential participants were screened by a General Practitioner (GP) from each practice to exclude patients who would be unable to participate in an interview due to severely impaired performance status. Practices sent letters of invitation, study information, reply slips and reply paid envelopes to those eligible. Information packs were also enclosed for caregivers.

Caregivers included any adult involved in providing care or assistance to the individual experiencing cancer pain, such as a partner, family member or close friend. Patients were asked to invite one of their caregivers to

\begin{tabular}{|c|c|c|c|c|c|c|c|}
\hline Pseudonym & Age (years) & Sex & $\begin{array}{l}\text { Primary cancer } \\
\text { site }\end{array}$ & $\begin{array}{l}\text { Distant } \\
\text { metastases }\end{array}$ & $\begin{array}{l}\text { Caregiver } \\
\text { pseudonym }\end{array}$ & $\begin{array}{l}\text { SIMD } 2012 \\
\text { decile*18 }\end{array}$ & $\begin{array}{l}\text { Sixfold urban rural } \\
\text { classification }{ }^{19}\end{array}$ \\
\hline Christine & 73 & $\mathrm{~F}$ & Breast & Yes & Jack, husband & 8 & 1: Large urban area \\
\hline Kevin & 72 & M & $\begin{array}{l}\text { Haematological } \\
\text { (non-Hodgkin's } \\
\text { lymphoma) }\end{array}$ & Yes & Joan, wife & 9 & 3: Accessible small town \\
\hline Tim & 66 & M & $\begin{array}{l}\text { Renal and } \\
\text { pancreatic } \\
\text { primaries }\end{array}$ & Yes & $\begin{array}{l}\text { Victoria, } \\
\text { daughter }\end{array}$ & 6 & 2: Other urban areas \\
\hline Richard & 70 & M & Prostate & Yes & $\mathrm{N} / \mathrm{A}$ & 7 & 3: Accessible small town \\
\hline David & 56 & M & Colorectal & Yes & $\mathrm{N} / \mathrm{A}$ & 6 & 1: Large urban area \\
\hline Alex & 67 & M & Prostate & Yes & N/A & 5 & 5: Accessible rural \\
\hline Zoe & 69 & $\mathrm{~F}$ & Ovary & Yes & $\mathrm{N} / \mathrm{A}$ & 4 & 1: Large urban area \\
\hline Ruth & 57 & $\mathrm{~F}$ & Lung & Yes & $\mathrm{N} / \mathrm{A}$ & 2 & 1: Large urban area \\
\hline John & 62 & M & $\begin{array}{l}\text { Gastro- } \\
\text { oesophageal } \\
\text { junction }\end{array}$ & Yes & Barbara, wife & 6 & 5: Accessible rural \\
\hline Robert & 61 & M & Oesophagus & Yes & N/A & 2 & 2: Other urban areas \\
\hline Andrew & 76 & M & Lung & No & Claire, partner & 9 & 5: Accessible rural \\
\hline Kirsty & 56 & $\mathrm{~F}$ & Colorectal & Yes & N/A & 9 & 3: Accessible small town \\
\hline Jason & 66 & M & Oesophagus & No & N/A & 4 & 2: Other urban areas \\
\hline Campbell & 68 & M & Lung & Yes & Dorothy, wife & 10 & 1: Large urban area \\
\hline
\end{tabular}




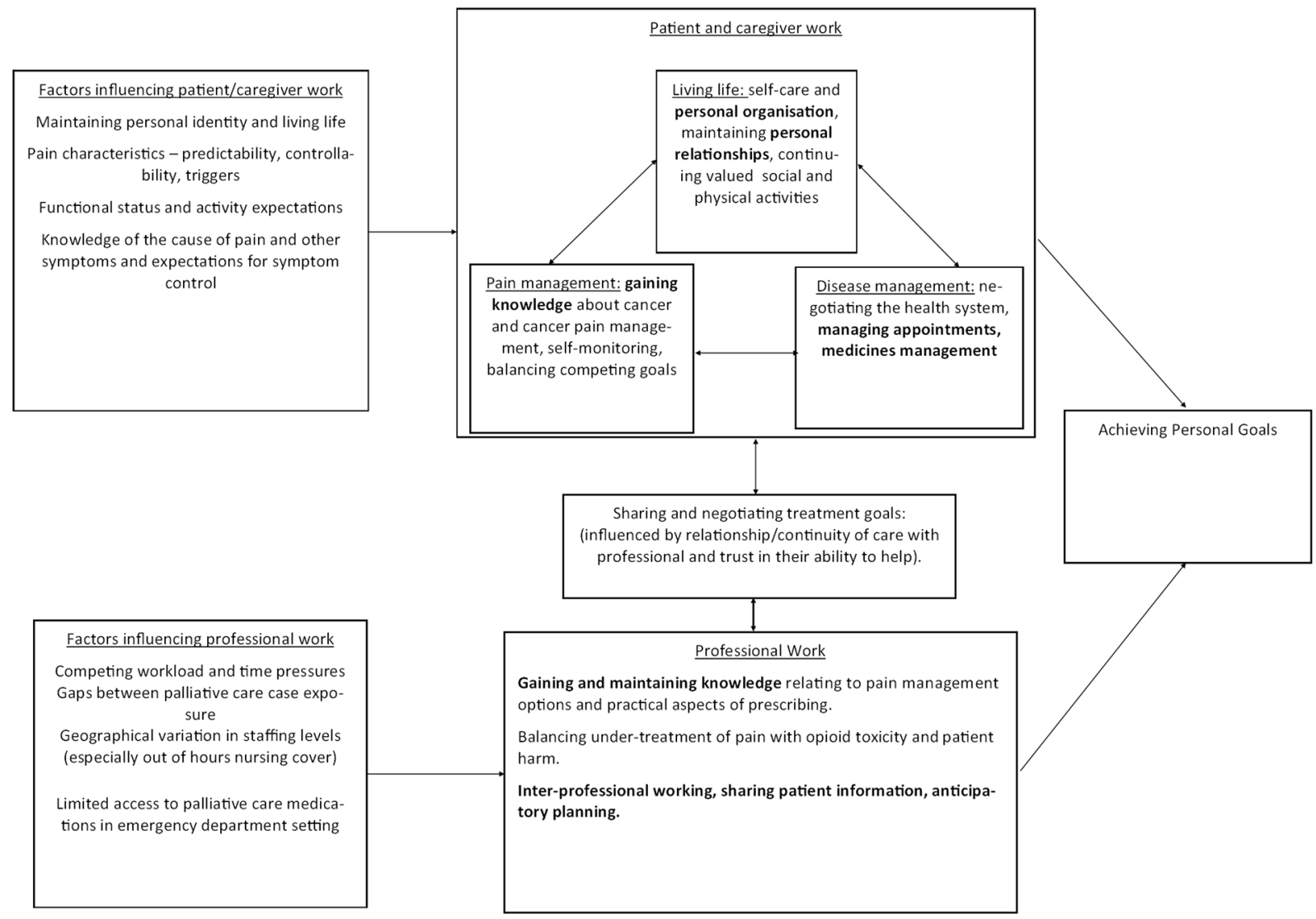

Figure 1 The context and work of cancer pain management for patients, caregivers and professionals. Areas in which qualitative data suggested that digital tools are already influencing management are highlighted in bold.

participate. All interested participants replied directly to the research team.

Professionals were doctors, nurses and pharmacists involved in cancer pain management. Professionals were based in NHS Grampian and were identified from the Managed Clinical Network for cancer, GP OOH service, local hospice, community pharmacy palliative care network and Macmillan nursing service. Professionals were invited by email. Further professionals were identified by snowball sampling (interested professionals recommended other relevant professionals). No attempt was made to match patients to their treating professionals. Instead, a wide range of professionals from different settings were invited.
Data generation, management and analysis

Semistructured interviews and focus groups were conducted according to schedules (appendix 1), which mapped enquiries to the study aims. Interview and focus group schedules were structured in two parts. The first part focused on cancer pain, the behaviours necessary to accomplish pain management and the factors driving and modifying these behaviours. The second part asked about current use of digital technologies in general, and ideas and preferences for using digital technologies to assist with cancer pain management.

Interviews were conducted face to face in a mutually convenient location or by telephone according to participant preference. All interviews and focus groups were

\begin{tabular}{lll}
\hline Table 2 Professional participants & & \\
\hline Professional background, $n(\%)$ & $\begin{array}{l}\text { Specialty of professionals participating in } \\
\text { interview, }(n)\end{array}$ & $\begin{array}{l}\text { Specialty of professionals participating in } \\
\text { focus group, }(n)\end{array}$ \\
\hline Doctors, $n=17(55)$ & $\begin{array}{l}\text { General practitioners }(n=12) \text { Specialty doctors in } \\
\text { accident and emergency medicine }(n=2) \\
\text { Consultant in accident and emergency medicine } \\
(n=1)\end{array}$ & Consultant in palliative care medicine $(n=1)$ \\
& $\begin{array}{l}\text { Consultant in anaesthesia and pain medicine ( } n= \\
\text { 1) }\end{array}$ & \\
Nurses, $n=12(39)$ & $\begin{array}{l}\text { Specialist palliative care nurses, hospice and } \\
\text { hospital ( } n=2)\end{array}$ & $\begin{array}{l}\text { Macmillan nurses }(n=9) \\
\text { Urology specialist nurse }(n=1)\end{array}$ \\
Pharmacists, $n=2(6)$ & Community pharmacist $(n=1)$ & Palliative care pharmacist $(n=1)$
\end{tabular}


conducted by one author (RA), audio recorded, transcribed verbatim and imported into NVivo Version 10.

Data familiarisation took place during transcription and by reading and re-reading transcripts. Interview and focus group data were analysed using a combination of Framework analysis ${ }^{15}$ and thematic analysis, ${ }^{16}$ which took place in tandem. Framework analysis was used to organise and structure the data. Subject headings were taken from interview and focus group schedules. Data were indexed against subject headings, allowing researchers to see what each participant had said about main topics. Thematic analysis was conducted on both the Framework matrices and full transcripts of focus groups and interviews. Emergent themes were discussed during regular meetings. Themes were constantly refined and revised as new data were collected. In this way, analysis was influenced by prior ideas (schedules and Framework matrices), but was flexible and determined by the data itself. Interviews were conducted until data saturation was reached, which was predefined as two successive interviews in which no new themes were identified. ${ }^{17}$

\section{Ethical/NHS Research and Development Approval}

Those participating in face-to-face interviews and focus groups gave written consent. Audio-recorded verbal consent was given for telephone interviews. Approvals were granted by North of Scotland Regional Ethics committee and NHS Grampian Research and Development Office (reference 15/NS/0002).

\section{RESULTS}

\section{Participants and demographics}

Eight out of 13 (62\%) general practices approached agreed to participate. Electronic clinical record searches identified 114 potential patient participants. After GP screening, 71 invitations were sent to eligible patients with 17 responses (24\%). Interviews were held with 14 patients, including 6 with their caregivers (usually partners) present. One respondent could not be contacted, one replied that their pain was no longer cancer related and one declined. Thirteen patient/caregiver interviews were face to face and one was by telephone. Interviews lasted between 26 and 72 min (mean $53 \mathrm{~min}$ ). Patients were aged between 56 and 76 years, mean 66 years. Patient demographics are summarised in table $1 .{ }^{18}{ }^{19}$ Participants are uniquely identified by pseudonyms.

It was not possible to calculate professional response rates as email invitations were sent by network managers. Thirty one professionals participated. Their backgrounds are summarised in table 2. Nineteen professionals took part in interviews (15 face to face and four telephone interviews), and 12 took part in one of two focus groups. Professional interviews lasted between 23 and $50 \mathrm{~min}$ (mean $31 \mathrm{~min}$ ). Focus groups lasted between 47 and $50 \mathrm{~min}$.

\section{Thematic analysis}

Themes were organised overall within two overarching categories: 'the work of managing cancer pain and its context', and 'digital tools to help with this work'. The work of managing cancer pain is summarised diagrammatically in figure 1 , which also highlights areas mentioned by participants in which digital technologies are already being used to help with this work.

In the descriptions below, verbatim quotes are identifiable by italicised text and by the participant role and pseudonym or professional background.

\section{The work of managing cancer pain and its context}

Patients gave accounts of cancer and cancer-related pain as burdensome conditions that required effort and hard work to manage them. Pain management for patients and caregivers was only one area of work and was described in the context of managing cancer overall, and the tasks that were necessary to continue living life and participating in valued activities despite pain and cancer. Caregivers helped with all aspects of this work.
John (patient): I really feel sorry for anybody who lives on their own and has cancer because it must be a nightmare for them organizing all their hospital visits and going to the chemist and remembering their tablets and remembering, ken, their appointments, and
Barbara (caregiver): Preparing food
John: Aye, and preparing, looking after yourself at the same time, (...) It wouldn't be such a great thing looking after yourself with cancer, (...) it's a full time job cancer management.

\section{Accomplishing personal goals}

Complete amelioration of pain was not the main goal for most patients. Pain was considered alongside functional and activity goals, overall symptom burden and medication side effects. The main behaviours necessary to accomplish personal goals included gaining knowledge and understanding about cancer and cancer pain; self-monitoring of pain; balancing competing goals; and communicating with professionals.

Gaining knowledge and understanding about cancer and pain. Patients and caregivers gave accounts of arriving at an understanding of their diagnosis and its role in causing their pain. For several patients, pain had been at its worst before their cancer diagnosis and had been a presenting symptom of late disease. Unexplained pain was particularly difficult to manage, but subsequently acquiring knowledge about the nature of the disease and being able to attribute a cause to the pain was an important step in self-management.

Richard (patient): it was about sixmonths before the cancer was diagnosed (...) they [the GPs] said it was sciatica so I took their word for it (...) I was going to physio', I was given exercises, I did these exercises and it was making no difference you see. I 
understand now. (...) It's there, I've accepted it (...)

I just get on with whatever I'm doing, and that's it.

Self-monitoring of pain. Patients with similar diseases and demographics had wide variations in their experiences of pain with respect to the nature, intensity, patterns, response to analgesia and satisfaction with pain control. Unpredictable pain was associated with fear and was particularly difficult to control. Some patients (and caregivers) kept written notes of pain, associated symptoms such as nausea and breakthrough analgesic use. Others recognised patterns based on experience over time. One caveat to self-monitoring was that distraction or ignoring pain was a self-management strategy. However, those who recognised patterns or triggers for pain were often able to manage pain around their own acceptable level.

Christine (patient): it's if I've been standing for a while, (...) when I walk about or stand for a certain time. It's certain things that I do that gives me the pain (...) I try not to think about it too much, you know, [I] might get more involved in the thinking, ken, in your head: 'oh the pain's really bad', you know? You've just got to handle it. I know the things that I'm doing that gives me more pain.

Balancing competing goals: pain, analgesic side effects and living life. Pain was never considered in isolation. Patients had their own priorities and activities that they valued which helped them to continue to live their lives. These priorities could be at odds with using analgesics to control pain. Analgesic side effects, particularly constipation and central nervous system side effects, and the addition of extra medications to control analgesic side effects contributed to overall symptom burden.

Andrew had severe pain on movement but valued playing golf. He decided to accept a level of pain to avoid opioid side effects (constipation, hallucinations and urinary side effects), to continue driving and playing golf. Similarly, Alex valued an active lifestyle and was renovating his home. Physical activity exacerbated bony pain, but breakthrough opioid use was associated with constipation and emotional lability. He made careful self-management decisions to manage physical work, analgesia and side effects.

Alex (patient): up until two years ago, I led a very active life, (...) I find, as long as I'm doing nothing, the hundred a day [of long acting morphine] is fine, but I can't sit about doing nothing. So I try to do as much as I can, but an hour, an hour and a half and I have to take morphine, (...) then I have to relax until the morphine kicks in and I'm not feeling any pain anymore (...) the pain control causes other problems.

Communicating with professionals. The extent that patients involved professionals in formulating and managing treatment goals was influenced by continuity of care with a particular professional and by the level of trust that the patient had in their professional's ability to help.

\begin{abstract}
Christine (patient): [I] haven't been to the GP for ages cause I just feel, well what can he do? We just keep phoning up for repeat prescriptions (...) None of the doctors down there have seen me for ages. If you said my name to them, they wouldn't even know what I looked like probably. I'm just a record to them. You know? I'm just a number in a way.
\end{abstract}

\section{Accomplishing professional goals}

The notion that patients had individual preferences for balancing pain with analgesic side effects and valued activities was partly echoed in enquiries with some professionals, who acknowledged their key role in supporting patients to achieve individual treatment goals.

Nurse manager, hospice (professional interview 5). Some people are fearful [of pain] and will immediately want something whereas other patients think, mm, that little bit of control, I'll just see what happens here, because sometimes they still maybe want to go out and do something and they think: maybe if I take a pain killer then actually I might be a bit groggy (...) they have that balance of thinking what they want to do, and that's their choice and that needs to be respected a lot of the time.

For other professionals, the main goal was to alleviate pain. There was a sense that patient non-adherence to analgesics could usually be overcome by educating patients about the necessary role of analgesics.

Out of hours GP (professional interview 10): we do get calls relatively frequently from patients who say they're in pain but they haven't taken anything (...) we have to say: 'well, why have you not taken your medication today? You know, that's what it's for'. 'Oh I don't like to take it I just get constipated'. 'Well if you want to control the pain then you have to take the medication as it's prescribed'.

\section{Professional work and behaviours to support pain management}

The main work described by professionals was acquisition and maintenance of knowledge about treatment options available to manage pain, and practical aspects of prescribing, such as how and when to convert from one opioid to another. Emergency department physicians all described lack of knowledge as a barrier to good cancer pain management in the emergency department.

\footnotetext{
Emergency Department Consultant (Professional interview 3). From an emergency department perspective it's not an ideal place to come with a cancer pain problem. We've got limited knowledge and expertise I think with regard to the drugs that are used for treating cancer pain.
} 
Professional work also involved ensuring adequate assessment of pain, and balancing undertreatment of pain with opioid toxicity and other opioid-related harms. The subjective nature of pain and patient's individual thresholds created difficulties for professionals in making judgements about pain prescriptions.

GP partner (professional interview 18): it's not like you're assessing a sodium [level] and you watch the sodium go up and down. With pain it's so subjective anyway so if the patient doesn't want to tell me or wants to put on a brave face, or alternatively is getting secondary benefit. I've got a patient who's on lots of opioids who I think probably likes the kind of feeling'

Professionals gave insights into factors that influenced pain management at a health system level. These factors are summarised in figure 1.

\section{Digital tools to help with the work of managing cancer pain}

If cancer and cancer pain management were considered work, digital technologies were potential tools. Patients drew comparisons between older or existing tools: some used paper notebooks to monitor symptoms.

John (patient): It's just a different way of doing things (...), just because you can work on a computer doesn't make you any more intelligent than a man working on an abacus. A computer is just a glorified abacus at the end of the day.

\section{Engagement with digital technologies in general}

There was a spectrum of engagement with digital technology in general among patients and caregivers. Most patients were regularly using computers, tablets or smartphones and had internet connections. Patients were using digital technologies for four main purposes: convenience (eg, online shopping, remote banking); personal organisation; knowledge and information; and communicating with others. In this way, technologies were already being used to help with the work of living with cancer, maintaining valued activities and living life.
Kirsty (patient): I'm on Facebook (...) it can lift your spirits (...) although you're on your own you feel you're, because you're commentating to somebody about whatever, you feel that you're part, you're still part of the world, you're not stuck here on your own (...) I do find it quite supportive, and of course the internet's there twenty four seven

Some patients had no desire to engage with digital technologies. The main barriers to engagement were lack of interest and technology not fitting with their lifestyle. Additional barriers mentioned by patients and professionals are summarised in table 3.

\section{Ideas and preferences about digital tools for cancer and pain management}

Professionals and patients already recognised that electronic clinical records and computerised anticipatory care plans had improved informational continuity and communication between primary and secondary care.

\section{Alex (patient): after I'd seen my Consultant, I had to see the practice nurse about something, and it was only two days later that all the information that I'd given to the Consultant was up there on the computer in front of her.}

More engaged patients had ideas for digital pain management tools that reflected the areas of work involved in cancer pain management, namely as sources of information and knowledge, as symptom monitoring tools which could stimulate help seeking and to help with medicines management (particularly for reminders and prompts).

Patients and caregivers were using a variety of internet resources for disease-related information and to validate and expand on information from professionals. There was a sense that the information was easily available, and accessible in various formats (videos, forums, etc). Patients and caregivers felt able to judge how reliable the information was, and valued

\begin{tabular}{|c|c|}
\hline $\begin{array}{l}\text { Patient and caregiver perspectives on barriers to digital } \\
\text { engagement }\end{array}$ & Professional perspectives on barriers to digital engagement \\
\hline Increasing age and lack of familiarity & Older and frailer patients \\
\hline Lack of interest, does not fit within current lifestyle & $\begin{array}{l}\text { Unsuitable for patients with cognitive impairment or decreased conscious } \\
\text { levels }\end{array}$ \\
\hline $\begin{array}{l}\text { Financial costs of purchasing technology and maintaining internet } \\
\text { connection }\end{array}$ & Potential for technological interventions to add to professional workload \\
\hline Interaction with technology is stressful & $\begin{array}{l}\text { Practical barriers of integrating digital data into NHS systems and } \\
\text { infrastructure }\end{array}$ \\
\hline Concerns about personal data security (mainly financial data) & Culture of resistance to change within NHS \\
\hline Low levels of literacy & $\begin{array}{l}\text { Technology can detract from human aspect of medicine and face-to-face } \\
\text { communication with patients }\end{array}$ \\
\hline $\begin{array}{l}\text { Less likely to feel like interacting when in pain or generally unwell, potential } \\
\text { to be burdensome. If used regularly for symptom monitoring may draw } \\
\text { attention to symptoms }\end{array}$ & Inconsistent access to cellular data signal in rural locations \\
\hline
\end{tabular}


the ability to choose how much factual detail and reality they were faced with.

Dorothy (caregiver): I went on my tablet to try and understand a wee bit about what he had (...) and the meaning of, you get all these big words and you really don't understand them ... Campbell has an adenocarcinoma of the lung. I found it upsetting.... it made me kind of understand what it was... I started wondering about, how has this happened? How has it formed? Where did it come from? How is it surviving? I wanted to know that.

One patient was using calendar and alarm functions on his smartphone to prompt long-acting morphine dosing, and to organise hospital appointments. None of the participants were using digital technologies for symptom monitoring. Patients felt more comfortable using paper notebooks to track pain and analgesic use, but some spoke about potential advantages of digital monitoring, particularly in relation to recognising worsening trends for pain or analgesic use, and as a way to automatically prompt action by a professional.

Andrew (patient): if I mentioned on one particular day it [pain severity] was six, five, whatever the case may be, and that was being referred back to a recognition centre and someone would say 'oops, there's something going wrong here (...) we'd better look into it', that would be an ideal application for me.

A key concern for all participants was that digital tools should add value over paper resources, and that they should be simple to use and not time or work intensive.

\section{DISCUSSION}

\section{Main findings}

Successful cancer pain management is about more than reducing pain intensity. Patient treatment goals are highly individual, and self-management behaviours involve balancing pain with medication side effects and activities. Professionals recognise individual treatment goals to varying extents.

Cancer is burdensome and those with advanced disease are engaged in hard work managing symptoms and continuing to live life. Digital technologies are convenient and have already been adopted by some patients with advanced cancer to make life easier and fuller (eg, remote shopping and banking, video calls with loved ones). With respect to symptom management, digital technologies are arguably underutilised. Patients are using the internet as a resource for knowledge, but turn to pen and paper to track symptoms and breakthrough use, and use traditional lines of communication (sometimes less than optimally) with medical professionals. Barriers to engagement with technology (table 3) exist at patient, professional and health system levels. There are a subset of patients who are unfamiliar with digital technologies, who find interacting with them stressful and who are not interested in integrating them into their lifestyle. NHS infrastructures and difficulties changing established working practices are also major barriers, and both patients and professionals share the concern that digital systems could add to work and burden.

\section{Comparison with existing literature}

It has previously been demonstrated that cancer pain is a variable and dynamic experience ${ }^{20}$ and that analgesic adherence can be reduced when side effects interfere with patients' lives. ${ }^{21}$ Interventions have focused on improving pain control by reducing barriers to analgesic adherence. ${ }^{22}{ }^{23}$ We found that patients took a much broader perspective to analgesic utilisation based on individual treatment goals.

Our themes have important parallels with literature describing the work involved in self-managing chronic illnesses, ${ }^{24}$ which includes maintaining valued social roles and a sense of normality. ${ }^{25}$ Our study suggests that these self-management principles apply in the palliative care setting. Our findings fit with research that recognises that patients and caregivers are burdened and put under demand by treatment regimens and healthcare systems. ${ }^{26}$

Questions have been raised about the acceptability of digital interventions in patients with advanced cancer. Cox $\mathrm{et}_{\mathrm{al}} \mathrm{l}^{27}$ developed a digital intervention to support symptom monitoring after palliative radiotherapy in patients with lung cancer, but most clinicians would not give approval for their patients to be recruited to test the intervention, arguing that the patient population were too elderly and unwell. We have shown that advanced, symptomatic cancer is not in itself a barrier to technological interventions.

\section{Strengths and limitations}

Our study generated approximately 24 hours of thematically rich audio-recorded data, incorporating views from key informants from multiple backgrounds, including those with advanced, symptomatic cancers (considered to be hard to reach). Combined use of interviews and focus groups allowed the topic to be explored in complementary ways, and through detailed discussion and debate, reach a coherent and inclusive understanding of the phenomenon (triangulation). There was value in recognising and responding to emerging themes throughout the study: our focus moved away from medication adherence and potential interventions to support this towards the idea of personal treatment goals.

The study was undertaken in a single geographical area with limited participants, and findings may not be generalisable to all patients with pain in every setting. Professionals were not matched to patients. Matching could have highlighted discrepant patient and professional perspectives, but may have limited our ability to reach professionals from wide-ranging backgrounds. 
All interviews and focus groups were conducted by RA, who is a general practitioner. Interviewer background can influence qualitative enquiries both positively and negatively. ${ }^{28}$ All authors were involved in analysis, reducing the risk that a single researcher might have introduced biases.

\section{Implications for practice, policy and research}

Our research comes at a time when there is great interest in using PROMs to improve patient-cent red cancer care, ${ }^{29} 30$ and a move towards using digital technologies to capture and communicate patient-reported data. ${ }^{713}$ For pain management interventions, a key finding is that overall reductions in pain intensity may not be the most important outcome measurement to the patient. Interventions that strive to effect meaningful improvements in pain and symptom management should consider patient reports of medication (particularly analgesic) side effects and function, in addition to pain.

Given that symptom management goals are unique to the individual, technological solutions should promote tailored care. An advantage of digital symptom reporting is that questions could be adapted (eg, some missed out or added) based on previous responses (computerised adaptive testing). It may be possible to allow patients to set their own thresholds of what is acceptable to them within digital symptom monitoring tools. This could promote dialogue between patients and professionals about discrepant symptom management expectations and goals.

\section{CONCLUSIONS}

Cancer pain management is hard work and takes place in the context of multiple, sometimes competing personal goals. Opportunities exist to augment and adapt the ways that digital technologies are already being used by patients with cancer to support personalised symptom monitoring and patient-professional communication. The challenge is for digital solutions to add value to pain and symptom management without unnecessarily adding to patient, caregiver and professional work.

Acknowledgements The authors thank the patients, caregivers and professionals who took the time to participate in this study, and Hazel Riley, secretary for her assistance with transcription. The authors also thank Amanda Cardy from the Scottish Primary Care Research Network for her help with patient recruitment.

Contributors RA was involved in the conception and design of this study, carried out all qualitative enquiries, analysed the data and wrote the paper. $\mathrm{MdB}, \mathrm{CMB}, \mathrm{CDB}$ and PM were involved in designing the study, analysing qualitative data and revising the article critically. MGC was involved in qualitative data analysis and revising the article critically.

Competing interests None declared.

Patient consent Patient data have been fully anonymised in this report. All participants gave informed consent to participate in this qualitative study.
Ethics approval North of Scotland Research Ethics Committee.

Provenance and peer review Not commissioned; externally peer reviewed.

Open Access This is an Open Access article distributed in accordance with the Creative Commons Attribution Non Commercial (CC BY-NC 4.0) license, which permits others to distribute, remix, adapt, build upon this work noncommercially, and license their derivative works on different terms, provided the original work is properly cited and the use is non-commercial. See: http://creativecommons.org/licenses/ by-nc/4.0/

(C) Article author(s) (or their employer(s) unless otherwise stated in the text of the article) 2018. All rights reserved. No commercial use is permitted unless otherwise expressly granted.

\section{REFERENCES}

1 van den Beuken-van Everdingen MH, de Rijke JM, Kessels AG, et al. Prevalence of pain in patients with Cancer: a systematic review of the past 40 years. Ann Oncol 2007;18:1437-49.

2 Gunnarsdottir S, Donovan HS, Serlin RC, et al. Patient-related barriers to pain management: the Barriers Questionnaire II (BQ-II). Pain 2002;99:385-96.

3 Potter VT, Wiseman CE, Dunn SM, et al. Patient barriers to optimal Cancer pain control. Psychooncology 2003;12:153-60.

4 Oldenmenger WH, Sillevis Smitt PA, van Dooren S, et al. A systematic review on barriers hindering adequate cancer pain management and interventions to reduce them: a critical appraisal. Eur J Cancer 2009;45:1370-80.

5 Marie Curie Policy and Public Affairs. Difficult conversations with dying patients and their families. https://www.mariecurie. org.uk/globalassets/media/documents/s691-difficultconversations-report.pdf (accessed 6 May 2016).

6 Adam R, Clausen MG, Hall S, et al. Utilising out-of-hours primary care for assistance with cancer pain: a semi-structured interview study of patient and caregiver experiences. $\mathrm{Br} \mathrm{J} \mathrm{Gen}$ Pract 2015;65:e754-e760.

7 Taylor S, Allsop MJ, Shaw J, et al. The feasibility of Collecting Patient reported Pain Data using a System Delivered across four modes of technology. Pain Med $2015 ; 16: 2212-3$.

8 Ruland CM, Andersen T, Jeneson A, et al. Effects of an internet support system to assist cancer patients in reducing symptom distress: a randomized controlled trial. Cancer Nurs 2013;36:6-17.

9 Post DM, Shapiro CL, Cegala DJ, et al. Improving symptom communication through personal digital assistants: the CHAT (Communicating Health Assisted by Technology) project. J Natl Cancer Inst Monogr 2013;2013:153-61.

10 Cleeland CS, Wang XS, Shi Q, et al. Automated symptom alerts reduce postoperative symptom severity after cancer surgery: a randomized controlled clinical trial. J Clin Oncol 2011;29:994-1000.

11 Anderson KO, Palos GR, Mendoza TR, et al. Automated pain intervention for underserved minority women with breast cancer. Cancer 2015;121:1882-90.

12 Berry DL, Blumenstein BA, Halpenny B, et al. Enhancing patient-provider communication with the electronic selfreport assessment for cancer: a randomized trial. J Clin Oncol 2011;29:1029-35.

13 Allsop MJ, Taylor S, Mulvey MR, et al. Information and communication technology for managing pain in palliative care: a review of the literature. BMJ Support Palliat Care 2015;5:481-9.

14 Leykum LK, Pugh JA, Lanham HJ, et al. Implementation research design: integrating participatory action research into randomized controlled trials. Implement Sci 2009;4:69. 
15 Ritchie J, Lewis J. Qualitative research practice a guide for social science students and researchers. 1st ed. London: Sage, 2003.

16 Joffe H, Yardley L. Content and thematic analysis. In: Marks DF, Yardley L, ed. Research methods for clinical \& health psychology. London: Sage publications, 2004.

17 Francis JJ, Johnston M, Robertson C, et al. What is an adequate sample size? operationalising data saturation for theory-based interview studies. Psychol Health 2010;25:1229-45.

18 Scottish Index of Multiple Deprivation 2012: General Report. Scottish Government, Edinburgh 2012. Available at http:// www.gov.scot/Topics/Statistics/SIMD (accessed 9 Jun 2016).

19 2011-2012 Urban Rural Classification. Data zone classification identifying urban and rural areas based on settlement size and drive times Update on 2009-2010 publication. Scottish Government, Edinburgh 2010. Available at htt p://www.gov.scot/Topics/Statistics/About/Methodology/ UrbanRuralClassification/Urban-Rural-Classification-2011-12 (accessed 9 Jun 2016).

20 Hackett J, Godfrey M, Bennett MI. Patient and caregiver perspectives on managing pain in advanced Cancer: a qualitative longitudinal study. Palliat Med 2016;30:711-9.

21 Manzano A, Ziegler L, Bennett M. Exploring interference from analgesia in patients with cancer pain: a longitudinal qualitative study. J Clin Nurs 2014;23:1877-88.

22 Adam R, Bond C, Murchie P. Educational interventions for cancer pain. A systematic review of systematic reviews with nested narrative review of randomized controlled trials. Patient Educ Couns 2015;98:269-82.

23 Miaskowski C, Dodd MJ, West C, et al. Lack of adherence with the analgesic regimen: a significant barrier to effective cancer pain management. J Clin Oncol 2001;19:4275-9.

24 Corbin JM, Strauss A. Unending work and care: managing chronic illness at home. San Francisco: Jossey-Bass, 1988.

25 Townsend A, Wyke S, Hunt K. Self-managing and managing self: practical and moral dilemmas in accounts of living with chronic illness. Chronic Illn 2006;2:185-94.

26 Mair FS, May CR. Thinking about the burden of treatment. BMJ 2014;10:349.

27 Cox A, Illsley M, Knibb W, et al. The acceptability of e-technology to monitor and assess patient symptoms following palliative radiotherapy for lung cancer. Palliat Med 2011;25:675-81.

28 Richards H, Emslie C. The 'doctor' or the 'girl from the University'? Considering the influence of professional roles on qualitative interviewing. Fam Pract 2000:17:71-75.

29 Kotronoulas G, Kearney N, Maguire R, et al. What is the value of the routine use of patient-reported outcome measures toward improvement of patient outcomes, processes of care, and health service outcomes in cancer care? A systematic review of controlled trials. J Clin Oncol 2014;32:1480-501.

30 Adam R, Burton CD, Bond CM, et al. Can patient-reported measurements of pain be used to improve cancer pain management? A systematic review and meta-analysis. BMJ Support Palliat Care 2016. 